\title{
Problems of Biofilms in Processed Cheese Factory
}

\author{
Amin, A. H.; Nazem, A. M. and Eman, Hassan, O.M.
}

Fac. Vet. Med., Alexandria University, Food Hygiene Dept., Egypt

\begin{abstract}
Bacteria in milk have the ability to adhere and aggregates on stainless steel surface, resulting in biofilm formation in milk processing environment lead to increased opportunity for microbial contamination of the processed dairy products by spoilage and pathogenic microorganisms. So, to detect the biofilm problem in processed cheese factory a total of 130 swabs were collected from the surface of equipment used in manufacture of processed cheese along the processing line after cleaning and sanitization ((mixing tank, cold storage tank, pre heating (head A, B), hot storage ,UHTsterilization(head A, B), flash tank, filter, creaming and hoopers ( Hooper 1,2,3) 10 samples from each from a manufacture plant in Alexandria Governorate. The samples were examined for aerobic mesophilic bacterial count, Coliforms, Staphylococcus aureus, Bacillus cereus and Clostridium perferingens. Bacillus and Clostridium species were failed to be detected in all examined samples. The most contaminated points with mesophilic aerobic bacteria were cold storage tank followed by Hooper (1) and flash tank. While, the highest contamination points with Coliforms were hooper (1) followed by cold storage tank and pre-heat head B. and finely, The highest contamination point with $S$. aureus were pre-heat head A followed by mixing tank and Hooper (2).

It is concluded that the good designing of food processing equipment and the selection of effective sanitation program with the rational running of processing line and frequent sanitation in short intervals are considered as solutions for lowering the incidence and minimizing the levels of biofilm formation.
\end{abstract}

Key words: Biofilm, processed cheese, Staphylococcus aureus, Bacillus cereus, Coliforms, $\mathrm{Cl}$. perfringens.

\section{Introduction}

Biofilms are aggregates of predominately bacterial cells attached to and growing on a surface (Costerton and Stewart, 2001). These biofilms are found in aqueous environments and are often resistant to disinfection. A biofilm form when bacteria begin to excrete a slimy, sticky substance that allows them to adhere to surfaces. An additional structural feature called the extracellular sticky substance (EPS) is what is thought to provide the biofilm with increased resistance to antimicrobial agents 
and biocides. The biofilm mass often varies with location within a given system, and is typically composed of many species of microorganisms , including bacteria, fungi, algae, and protozoa. It is also important to remember that about $85-96 \%$ of a biofilm consists of water, which means that only $2-5 \%$ of the total biofilm volume is detectable on dry surfaces (Costerton et al., 1981).

Biofilm formation is a dynamic process and different mechanisms are involved in its attachment, growth and colonization of microorganism on the milk contact surfaces. If these biofilms are not completely removed, they will increase the biotransfer potential (Mogha et al., 2014).

Under suitable conditions, a biofilm in a milk processing environment develops initially through accumulation of organic matter on a metal surface, which is then colonized by bacteria. Transition from planktonic mode to biofilm mode is regulated by a variety of environmental and physiological triggers, such as quorum sensing, nutrient availability, and cellular stress. A biofilm community may comprise single and/or multiple species of bacteria and form a single layer or 3-dimensional structures. Biofilms are large, complex, and organized bacterial ecosystems in which water channels are dispersed providing passages for nutrient, metabolite, and waste product exchange (Sauer et al.,
2007). Some microbes naturally have a higher tendency to produce biofilm than others (Carpentier and Cerf 1993).

Biofilms are difficult to remove once initial adhesion occurs. Even small numbers of surviving organisms can regrow, damaging dairy products or putting a company's reputation at risk in the event of product recall due to negative health outcomes. Biofilms can also shelter disease - causing microorganisms, temperature resistant bacterial spores, which are normally inactivated readily in their planktonic or single cell form.

Bacterial attachment and the formation of biofilms appear to take place in different stages, such as formation of a conditioning layer, bacterial adhesion, bacterial growth, and biofilm expansion (Kokare et al., 2009).

Biofilms are problematic in dairy processing (Chen, et al., 2007).The bacterial biofilms create a number of serious problems for industrial fluid processing operations. Mechanical blockages, increased impedance of heat transfer processes and biodeterioration of the components of metallic and polymeric systems result in billions of dollars in losses each year to food industries, Microorganisms in biofilms catalyze chemical and biological reactions causing metal corrosion in pipelines and tanks, and they can reduce the heat transfer efficacy if biofilms become sufficiently thick at plate heat 
exchangers and pipelines. Mittelman, 1998 also reported that it is of utmost importance to sanitize the processing equipment taking into account both the inorganic composition of the deposits and also the constitutive microflora. Dairy biofilms are predominated by bacterial extracellular polymeric substances (EPS) and milk residues, mostly proteins and calcium phosphate.

Biofilm formation in dairy industry is always noted as threat which affects the product safety and thereby resulting in food borne illness. So, it is considered as an emergent public health concern throughout the world (Mogha et al., 2014).

The formation of biofilms on dairy industry equipment can lead to serious hygiene problems and economic losses due to food spoilage and equipment impairment (Bremer et al., 2006 and Gram, et al., 2007.).

The contaminating microorganisms can form biofilms that are difficult to eradicate and can act as a harbour and/or substrate for other microorganisms less prone to biofilm formation, increasing the probability of pathogen survival and further dissemination during food processing (Lapidot et al., 2006).

Dangerous biofilms were detected also in closed systems. Pathogenic microorganisms (from genera Bacillus, Staphylococcus, Escherichia coli and Enterobacter aerogenes) participated in the biofilm formation on the surfaces of a post-pasteurisation unit in a dairy plant. Moreover, the isolates were often resistant to carbenicillin, cloxacillin, cephaloridin, novobiocin, and vancomycin (Sharma and Anand 2002). Therefore, the present study was designed to detect the biofilm problem in processed cheese factory in Alexandria Governorate.

\section{Material and methods \\ 1-Collection of samples}

One hundred and thirty swabs were collected from the surface of equipment used in manufacture of processed cheese along the processing line after cleaning and sanitization. (mixing tank, cold storage tank, pre heating (head A, B), hot storage ,UHTsterilization(head A, B), flash tank , filter, creaming and hoopers ( Hooper 1,2,3) 10 samples from each and swabs collected and prepared according to swab contact method (Cotton and white, 1992). The samples were transferred as soon as possible to the laboratory with a minimum of delay to be examined.

2. Bacteriological evaluation: APHA (1992), and ICMSF (1982).

2. 1. Preparation of serial dilutions (APHA, 1992).

2. 2. Aerobic mesophilic count (APHA, 1992):

2. 3. Enumeration and Isolation of B. cereus using Plate count technique on Polymyxin Pyruvate Egg yolk Bromothymol blue agar 
(PEMBA)

7932.2:2004).

2. 4. Staphylococcus aureus count (Lancette and Tatini, 1992)

2. 5. Enumeration of Coliforms on Violet Red Bile agar medium (VRB) (Mossel, et al., 1986).

2. 6. Isolation of Clostridial organisms from positive stormy fermentation test (ISO 7218, ISO
8261(2004) on reinforced Clostridia agar (RCM)

2. 7. Plate count of viable $\mathrm{Cl}$. perfringens on Tryptose Sulphite Cycloserine Agar Base (CMO587, $\mathrm{Cl}$. Perfringens selective agar with Perfringen (TSC) Selective Supplement (SR0088E) (ICMSF, 1982).

\section{Results}

Table (1): Statistical analytical results of Aerobic mesophilic bacterial count $(c f u / m l)$ of the examined swab samples from different steps in processed cheese processing line

\begin{tabular}{|l|c|c|c|c|}
\hline \multirow{2}{*}{ Site of processing line } & $\begin{array}{c}\text { No. of } \\
\text { examined } \\
\text { samples }\end{array}$ & \multicolumn{2}{|c|}{$\begin{array}{c}\text { Positive } \\
\text { samples }\end{array}$} & \multirow{2}{*}{ Mean \pm SEM } \\
\cline { 3 - 4 } & & No. & $\%$ & \\
\hline Mixing tank & 10 & 10 & 100 & $7.26 \times 10^{3} \pm 1.18 \times 10^{3}$ \\
\hline Cold storage tank & 10 & 10 & 100 & $2.47 \times 10^{4} \pm 1.03 \times 10^{4}$ \\
\hline Pre heating (head $\boldsymbol{A})$ & 10 & 10 & 100 & $8.11 \times 10^{3} \pm 2.53 \times 10^{3}$ \\
\hline Pre heating (head B) & 10 & 10 & 100 & $3.60 \times 10^{3} \pm 7.41 \times 10^{2}$ \\
\hline Hot storage tank & 10 & 8 & 80 & $4.75 \times 10^{3} \pm 1.46 \times 10^{3}$ \\
\hline UHT- sterilization(head $\boldsymbol{A})$ & 10 & 10 & 100 & $5.92 \times 10^{3} \pm 1.35 \times 10^{3}$ \\
\hline UHT- sterilization(head B) & 10 & 10 & 100 & $3.01 \times 10^{3} \pm 5.07 \times 10^{2}$ \\
\hline Flash tank & 10 & 9 & 90 & $3.10 \times 10^{4} \pm 5.85 \times 10^{3}$ \\
\hline Filter & 10 & 9 & 90 & $7.42 \times 10^{3} \pm 3.33 \times 10^{3}$ \\
\hline Creaming & 10 & 10 & 100 & $1.97 \times 10^{4} \pm 1.13 \times 10^{4}$ \\
\hline Hoopers $(\mathbf{1})$ & 10 & 10 & 100 & $8.82 \times 10^{4} \pm 2.73 \times 10^{4}$ \\
\hline Hoopers $(\mathbf{2})$ & 10 & 10 & 100 & $1.51 \times 10^{4} \pm 6.18 \times 10^{3}$ \\
\hline Hoopers $(3)$ & 10 & 10 & 100 & $3.72 \times 10^{3} \pm 1.06 \times 10^{3}$ \\
\hline
\end{tabular}




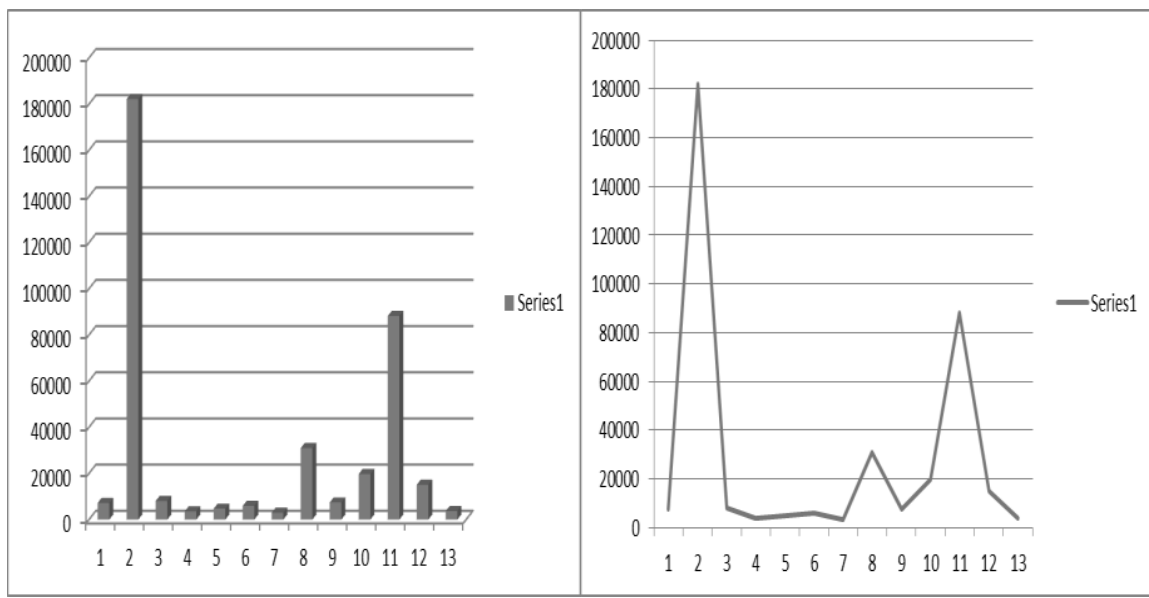

Figure (1): Aerobic mesophilic bacterial count (cfu/ml) in the examined swab samples from different steps in processed cheese processing line

Table (2): Statistical analytical results of Coliforms count $(\mathrm{cfu} / \mathrm{ml})$ of the examined swab samples from different steps in processed cheese processing line

\begin{tabular}{|l|c|c|c|c|}
\hline \multirow{2}{*}{ Site of processing line } & \multirow{2}{*}{$\begin{array}{c}\text { No. of } \\
\text { examined } \\
\text { samples }\end{array}$} & \multicolumn{2}{|c|}{$\begin{array}{c}\text { Positive } \\
\text { samples }\end{array}$} & \multirow{2}{*}{ Mean \pm SEM } \\
\cline { 3 - 4 } & No. & $\%$ & \\
\hline Mixing tank & 10 & 6 & 60 & $1.22 \times 10^{2} \pm 0.21 \times 10^{2}$ \\
\hline Cold storage tank & 10 & 4 & 40 & $1.8 \times 10^{2} \pm 0.75 \times 10^{2}$ \\
\hline Pre heating (head $\boldsymbol{A})$ & 10 & 1 & 10 & $3 \times 10$ \\
\hline Pre heating (head B) & 10 & 7 & 70 & $1.67 \times 10^{2} \pm 0.6 \times 10^{2}$ \\
\hline Hot storage tank & 10 & 2 & 20 & $1 \times 10$ \\
\hline $\begin{array}{l}\text { UHT- sterilization(head } \\
\text { A) }\end{array}$ & 10 & 7 & 70 & $0.6 \times 10^{2} \pm 0.25 \times 10^{2}$ \\
\hline $\begin{array}{l}\text { UHT- sterilization(head } \\
\text { B) }\end{array}$ & 10 & 8 & 80 & $7.38 \times 10 \pm 2.49 \times 10$ \\
\hline Flash tank & 10 & 7 & 70 & $1.42 \times 10 \pm 0.28 \times 10$ \\
\hline Filter & 10 & 4 & 40 & $2.9 \times 10 \pm 0.5 \times 10$ \\
\hline Creaming & 10 & 4 & 40 & $1 \times 10$ \\
\hline Hoopers (1) & 10 & 5 & 50 & $1.84 \times 10^{2} \pm 0.17 \times 10^{2}$ \\
\hline Hoopers (2) & 10 & 0 & 0 & 0 \\
\hline Hoopers (3) & 10 & 7 & 70 & $1.27 \times 10^{2} \pm 0.25 \times 10^{2}$ \\
\hline
\end{tabular}




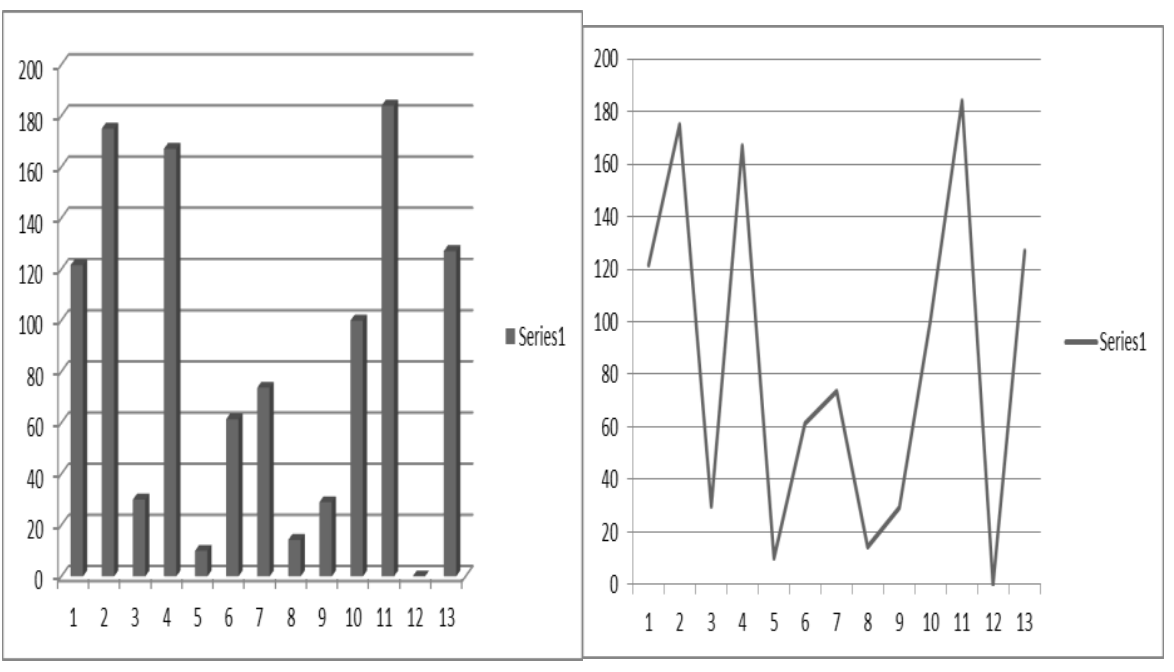

Figure (2): Coliforms ( $\mathrm{cfu} / \mathrm{ml})$ in the examined swab samples from different steps in processed cheese processing line

Table (3): Statistical analytical results of Staphylococcal count (cfu/ml) of the examined swab samples from different steps in processed cheese processing line

\begin{tabular}{|l|c|c|c|c|}
\hline \multirow{2}{*}{ Site of processing line } & $\begin{array}{c}\text { No. of } \\
\text { examined } \\
\text { samples }\end{array}$ & \multicolumn{2}{|c|}{$\begin{array}{c}\text { Positive } \\
\text { samples }\end{array}$} & \multirow{2}{*}{ Mean \pm SEM } \\
\cline { 3 - 4 } & No. & $\%$ & \\
\hline Mixing tank & 10 & 9 & 90 & $4.51 \times 10^{2} \pm 0.66 \times 10^{2}$ \\
\hline Cold storage tank & 10 & 4 & 40 & $2.25 \times 10 \pm 0.25 \times 10$ \\
\hline Pre heating (head A) & 10 & 6 & 60 & $10.4 \times 10^{2} \pm 3.57 \times 10^{2}$ \\
\hline Pre heating (head B) & 10 & 8 & 80 & $3.13 \times 10^{2} \pm 0.95 \times 10^{2}$ \\
\hline Hot storage tank & 10 & 4 & 40 & $1.5 \times 10 \pm 0.5 \times 10$ \\
\hline UHT- sterilization(head A) & 10 & 8 & 80 & $1.21 \times 10^{2} \pm 0.79 \times 10^{2}$ \\
\hline UHT- sterilization(head B) & 10 & 10 & 100 & $7 \times 10 \pm 1.7 \times 10$ \\
\hline Flash tank & 10 & 7 & 70 & $4.71 \times 10 \pm 1.52 \times 10$ \\
\hline Filter & 10 & 7 & 70 & $1.74 \times 10^{2} \pm 0.41 \times 10^{2}$ \\
\hline Creaming & 10 & 10 & 100 & $5.8 \times 10 \pm .1 .01 \times 10$ \\
\hline Hoopers (1) & 10 & 10 & 100 & $1.85 \times 10^{2} \pm 0.59 \times 10^{2}$ \\
\hline Hoopers (2) & 10 & 6 & 60 & $4.18 \times 10^{2} \pm 0.66 \times 10^{2}$ \\
\hline Hoopers (3) & 10 & 7 & 70 & $8.14 \times 10 \pm 3.77 \times 10$ \\
\hline
\end{tabular}




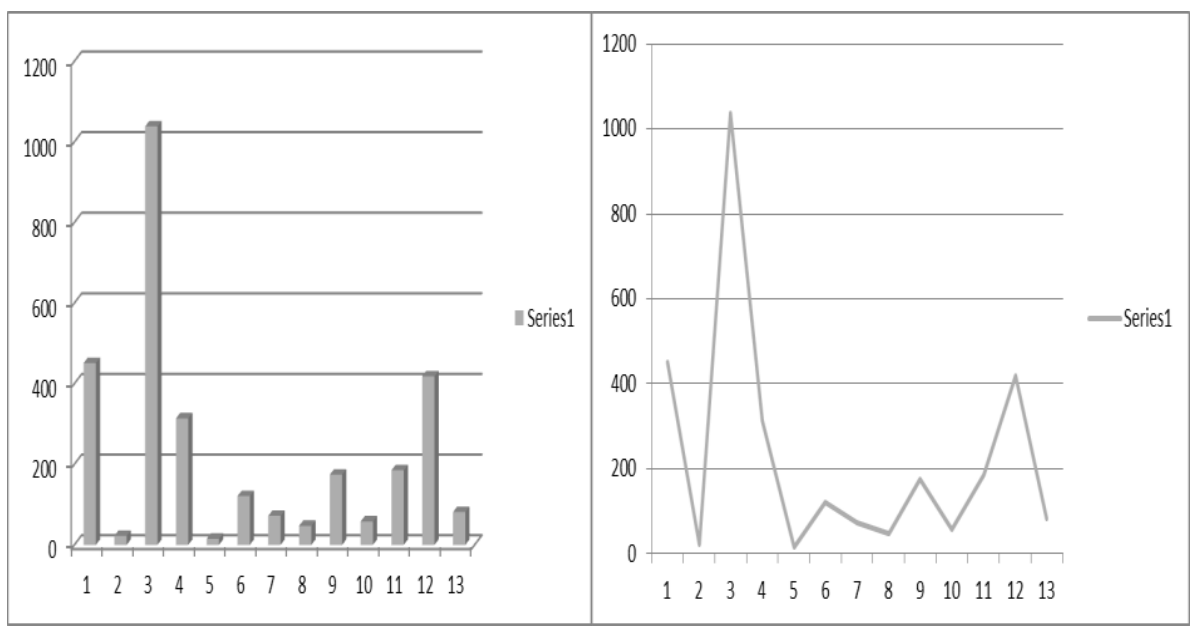

Figure (3): staphylococcal count (cfu/ml) in the examined swab samples from different steps in processed cheese processing line B.cereus and Clostridial spps. Failed to be detected in all the examined samples.

\section{Discussion}

Aerobic mesophilic bacterial count is used for assaying the overall quality and safety of milk and its product. It is useful indicator for monitoring the sanitary conditions applied during production, collection and handling of milk and dairy products.

Table (1) and figure (1) showed that Aerobic mesophilic bacterial count were present in $100 \%$ of examined samples of mixing tank, cold storage tank, pre-heat head A, preheat head B, UHT head A, UHT head B, creaming tank, hooper (1), hooper (2) and hooper (3) with mean value of $7.26 \times 10^{3} \pm 1.18 \times$ $10^{3}, 2.47 \times 10^{4} \pm 1.03 \times 10^{4}, 8.11$ $\times 10^{3} \pm 2.53 \times 10^{3}, 3.60 \times 10^{3} \pm$ $7.41 \times 10^{2}, 5.92 \times 10^{3} \pm 1.35 \times 10^{3}$, $3.01 \times 10^{3} \pm 5.07 \times 10^{2}, 1.97 \times 10^{4}$ $\pm 1.13 \times 10^{4}, 8.82 \times 10^{4} \pm 2.73 \times$ $10^{4}, 1.51 \times 10^{4} \pm 6.18 \times 10^{3}$ and
$3.72 \times 10^{3} \pm 1.06 \times 10^{3}$,respectively . While, 80, 90 and $90 \%$ of examined samples collected from hot storage, flash tank and filter were positive with mean value of $4.75 \times 10^{3} \pm 1.46 \times 10^{3}, 3.10 \times 10^{4}$ $\pm 5.85 \times 10^{3}$ and $7.42 \times 10^{3} \pm 3.33 \times$ $10^{3}$ respectively.

The most contaminated points were cold storage tank followed by hooper (1) and flash tank. The high figure of mesophilic aerobic count indicates failure in cleaning and sanitation procedures and the formed biofilm is considered as a protection layer for the most M.Os.

Table (2) and figure (2) showed that Coliforms value were present in $80 \%$ of examined samples collected from UHT head B with mean value of $7.38 \times 10 \pm 2.49 \times 10$, while $70 \%$ in the examined samples collected from preheating head B, UHT head $\mathrm{A}$ and hooper (3) with mean value 
of $1.67 \times 10^{2} \pm 0.6 \times 10^{2}, 1.42 \times 10$ $\pm 0.28 \times 10$ and $1.27 \times 10^{2} \pm 0.25 \times$ $10^{2}$, respectively. $60 \%$ of examined samples collected from mixing tank with mean value of $1.22 \times 10^{2} \pm 0.21$ $\mathrm{x} 10^{2}, 50 \%$ of examined samples collected from hooper (1) with mean value of $1.84 \times 10^{2} \pm 0.17$ $\mathrm{x} 10^{2}, 40 \%$ of examined samples collected from cold storage tank, filter and creaming tank with mean value of $1.8 \times 10^{2} \pm 0.75 \times 10^{2}, 2.9 \times$ $10 \pm 0.5 \times 10$ and $1 \times 10$ respectively. $20 \%$ of examined samples collected from hot storage tank with mean value of $1 \times 10$, $10 \%$ of examined samples collected from pre-heating head $B$ with mean value of $3 \times 10$ and were negative in all samples collected from hooper (2).

Coliforms count is considered as an indicator of possible feacal contamination, microbial quality and reflect the hygienic standards adapted in the food operation.

The highest contamination points with Coliforms were hooper (1) followed by cold storage tank and pre-heat head B.

Total Coliform Test-theoretically indicates the presence of all coliform group bacteria, both vegetative and fecal in origin. Its presence can be indicative of fresh pollution from human or animal waste though normally benign, some CDC (2012). Because many microbes from faeces are pathogenic in animals and humans, the presence of the intestinal bacterium E. coli in water and foods indicates a potential hygiene hazard. Most strains of E. coli are harmless. However, a few strains with wellcharacterised traits are known to be associated with pathogenicity. Those of greatest concern in water and foods are the intestinal pathogens, which are classified into five major groups: the enterohaemorrhagic $E$. coli (EHEC), the enterotoxigenic E. coli (ETEC), the enteroinvasive E. coli (EIEC), the enteropathogenic E. coli (EPEC) and the enteroaggregative E. coli (EAEC). Escherichia coli have been isolated from a large number of dairy products these agents can cause diarrhoeal outbreaks. E. coli can also survive for extended periods of time in several acidic foods, e.g. cheese and yogurt. Acid-adapted $E$. coli O157:H7 has shown enhanced survival and prevalence in biofilms on stainless steel surfaces (Venkitanarayanan and Doyle 2003).

Table (3) and figure (3) showed that $S$. aureus value were present in $100 \%$ of examined samples collected from UHT head B, creaming and hooper (1) with mean value of $7 \times 10 \pm 1.7 \times 10,5.8 \times 10$ $\pm .1 .01 \times 10$ and $1.85 \times 10^{2} \pm 0.59 \times$ $10^{2}$,respectively. $90 \%$ of examined samples collected from mixing tank with mean value of $4.51 \times 10^{2} \pm$ $0.66 \times 10^{2}, 80 \%$ of examined samples collected from pre-heating head B and UHT head A with mean value of $3.13 \times 10^{2} \pm 0.95 \times 10^{2}$ and $1.21 \times 10^{2} \pm 0.79 \times 10^{2}$,respectively. 
$70 \%$ of examined samples collected from flash tank, filter and hooper(3) with mean value of $4.71 \times 10 \pm 1.52$ $\mathrm{x} 10, \quad 1.74 \times 10^{2} \pm 0.41 \mathrm{x}$ $10^{2}$ and $8.14 \times 10 \pm 3.77 \times 10$ ,respectively. $60 \%$ of examined samples collected from pre-heating head A and Hooper (2) with mean value of $10.4 \times 10^{2} \pm 3.57 \times 10^{2}$ and $4.18 \times 10^{2} \pm 0.66 \times 10^{2}$, respectively. $40 \%$ of examined samples collected from cold storage tank and hot storage tank with mean value of $2.25 \times 10 \pm 0.25 \times 10$ and $1.5 \times 10 \pm 0.5 \times 10$, respectively. The highest contamination point with $S$. aureus were pre-heat head A followed by mixing tank and hooper (2).

However the source of $S$. aureus almost always originated from food handlers or from utensils previously contaminated by humans. The source of $S$. aureus almost always originated from food handlers or from utensils previously contaminated by human (Peters et al. 1999). S. aureus isolated in a total of $7 \%$ of food contact sites and $8 \%$ of environmental sites from 10 small and medium sized enterprises (Elvers et al. 1999).

B.cereus and Clostridia failed to be detected in all of the examined samples.

Bacteria within biofilms are protected from sanitizers due to multispecies cooperation and the presence of extracellular polymeric substance, by which their survival and subsequent contamination of processed milk product is promoted.
Modern food processing supports and selects for biofilm forming bacteria on food contact surfaces due to mass production of products, lengthy production cycles and vast surface areas for biofilm development. In situ biofilms have been recognized in various food processing industries, such as processors of cheese and milk products (O'Brien et al., 2004).

It is concluded that rational running of processing line, good production hygiene and the well-designed use of cleaning and decontamination processes are the most efficient means for limiting the growth of micro-organisms in the biofilm. And the cleanliness of surfaces, the training of personnel and the good manufacturing and design practices for combating biofilm problems in the food industry.

\section{References}

APHA, American Public Health Association (1992): Compendium of Methods for the Microbiological Examination of Foods, $3^{\text {rd }}$ Ed. Washington, DC, 20005.

Baier, R.E. (2006): "Surface behaviour of biomaterials: the theta surface for biocompatibility". J Mater Sci-Mater Med 17(11):1057-62.

Bremer, P., Suzanne Fillery, J. and James McQuillan, A. (2006): "Laboratory scale Clean-In-Place (CIP) studies on the effectiveness of different caustic and acid wash steps on the removal of dairy 
biofilms", Int. J. Food Microbiol. 106: 254-262.

Carpentier, B. and Cerf, $O$. (1993): "Biofilms and their consequences, with particular reference to hygiene in the food industry, J Appl Bacteriol, 75, 499-511.

Chen, J., Rossman, M. L. and Pawar, D. M. (2007): "Attachment of

enterohemorragic Escherichia coli to the surface of beef and a culture medium". LWT - Food Science and Technology, 40, 249-254.

COSTERTON, J. W., IRVIN, R. T. and CHENG, K-J. (1981): "The bacterial glycocalyx in nature and disease", Ann Rev Microbiol, 35, 299-324.

Costerton, J.W. and Stewart, P.S. (2001): "Battling Biofilms". Sci. Am., 285:74-81.

Cotton, L.N. and White, C.H. (1992): Listeria monocytogenes, Yersinia enterocolitica, and Salmonella in dairy plant environments. J Dairy Sci. 75(1):51-7.

CDC (2012): National Center for Emerging and Zoonotic Infectious Diseases. Retrieved 2012-10-02. "Escherichia coli".

ELVERS, K. T., PETERS, A. C. and GRIFFITH, C. J. (1999): "Development and control of biofilms in the food industry in Wimpenny J, Gilbert P, Walker J, Brading $\mathrm{M}$ and Bayston R Biofilms \pm the good, the bad and the ugly, Cardiff, BioLine, 139-145.

Gram, L., Bagge-Ravn, D., Ng, Y. Y., Gymoese, P., and Vogel, B. F. (2007): "Influence of food soiling matrix on cleaning and disinfection efficiency on

surface attached Listeria monocytogenes". Food Control, 18, 1165-1171.

ICMSF, International

Commission on Microbiological Specification of Foods (1982): Microorganisms in Foods, their significance and methods of enumeration. $2^{\text {nd }}$ Ed., Univ. Toronto Press, Toronto, Buffalo, London.

ISO 7218, (2004): Microbiology of food and animal feeding stuffs General rules for microbiological examinations.

ISO/FDIS/ 7932.2(2004, E): Microbiology of food and animal feeding stuffs Horizontal method for the enumeration of presumptive Bacillus cereus - Colony-count technique at Voting terminates on: $30{ }^{\circ} \mathrm{C}$.

Kokare, C.R., Chakraborty, S., Khopade, A.N. and Mahadik, K.R. (2009): "Biofilm: importance and applications. Indian. J. Biotechnol. 8(2):159-68.

Lancette, G. A. and Tatini, S.R. (1992): S.aureus, Ch.33. In: Compendium of Methods for Microbiological Examination of Foods. Vanderzant, C. and Splittoesser, D. (Eds) . American Public Health Association, Washington D.C. USA. 
Lapidot, A., Romling, U., and Yaron, S. (2006): "Biofilm formation and the survival of Salmonella typhimurium on parsley". International Journal of Food Microbiology, 109, 229-233.

Mittelman, M.W.

(1998): "Structure and functional characteristics of bacterial biofilms in fluid processing operations". J Dairy Sci 81(10):2760-4.

Mogha, K. V., Shah, N. P., Prajapati, J. B. and Chaudhari, A. R. (2014):

"Biofilm - A threat to dairy industry". REVIEW ARTICLE. Indian J. Dairy Sci. 67(6), 459-466.

O'Brien, S.S., Lindsay, D. and von Holy, A. (2004): "The presence of

Enterococcus, coliforms and E. coli in a commercial yeast manufacturing

process". International Journal of Food Microbiology, Vol. 94, pp. 23-31.
PETERS, A. C., ELVERS, K. T. and GRIFFITH, C. J. (1999): Biofilms in the food industry: Assessing hazards and risks to health in Wimpenny $\mathrm{J}$, Gilbert $\mathrm{P}$, Walker J, Brading $\mathrm{M}$ and Bayston $\mathrm{R}$ Biofilms \pm The Good, the Bad and the Ugly, Cardiff, BioLine.

Sauer, K., Rickard, A.H. and Davies, D.G. (2007): "Biofilms and biocomplexity". Microbe 2(7): 34755.

Sharma, M., and Anand, S. K. (2002a): "Characterization of constitutive

microflora of biofilms in dairy processing lines". Food Microbiology, 19, 627-636.

Venkitanarayanan, K. S. and Doyle, M. P. (2003): Escherichia coli, in Caballero B, Trugo L C and Finglas P M Encyclopedia of Food Sciences and Nutrition, 2nd edition, London, Academic Press, vol. 4, 2149-2152. 